\title{
STUDY PERENCANAAN PONDASI GEDUNG GUEST HOUSE 6 LANTAI DI KOTA KEDIRI
}

\author{
Supriyadi*1, Ahmad Ridwan ${ }^{2}$, Yosef Cahyo ${ }^{3}$. \\ ${ }^{1,2,3}$ Fakultas Teknik, Universitas Kadiri. \\ email : ${ }^{* 1}$ dhyadiii182@ gmail.com,${ }^{2}$ ahmad ridwan@unik-kediri.ac.id, \\ 3yosef.cs@unik-kediri.ac.id.
}

\begin{abstract}
The building foundation is a lower structure that functions to carry the weight of the load to the subgrade. The foundation planning study in this study uses a bore pile type of foundation. This study uses the Meyerhoff method based on SPT data received by CV. Arya Duta. In this bore pile foundation planning, the carrying capacity of the bore pile foundation to the ground is 81.00 tons, with a depth of 26 $M$ from the ground surface. The results of the calculation of pile drill piles get P 19.44 tons at the bottom of $26 \mathrm{M}$ while the reinforcement of the pile cap is found in q $1.152 \mathrm{Ton} / \mathrm{M}$ (own weight). In the bore pile with spiral support found the results of the analysis data ((D. concrete $600 \mathrm{~mm}$, Blanket $40 \mathrm{~mm}),(D$ reinforcement $16 \mathrm{~mm}$, number of reinforcement 10), (D. stirrup $10 \mathrm{~mm}$, Spacing $60 \mathrm{~mm})$ ). Based on the overall results of the structure, weight was found 16,771.43 Tons / M. Thus, from the analysis of equivalent lateral force loads (Fi 77.71), it was found that the construction of building structures is earthquake resistant.
\end{abstract}

Keywords : Building, Foundation, Meyerhoff, Bore Pile.

\begin{abstract}
Abstrak
Pondasi merupakan struktur bawah bangunan yang berfungsi meneruskan berat suatu beban pada bangunan ke tanah dasar. Study perencanaan pondasi pada penelitian ini menggunakan pondasi tipe bore pile. Penelitian ini menggunakan metode Mayerhoff berdasarkan data SPT yang di terima oleh CV. Arya Duta. Pada perencanaan pondasi bore pile ini didapatkan kemampuan daya dukung pondasi bore pile terhadap tanah adalah sebesar 81.00 Ton, dengan kedalaman $26 \mathrm{M}$ dari permukaan tanah. Hasil perhitungan tiang bor pile mendapatkan hasil P 19,44 Ton pada kedalaman $26 \mathrm{M}$. Sedangkan pada penulangan pile cap di temukan q 1,152 Ton/M (berat sendiri). Pada bore pile dengan tulangan spiral di temukan hasil data analisis ((D.beton $600 \mathrm{~mm}$, Selimut $40 \mathrm{~mm}$ ), (D tulangan $16 \mathrm{~mm}$, jumlah tulangan 10), (D. sengkang $10 \mathrm{~mm}$, Spasi $60 \mathrm{~mm}$ )). Berdasarkan hasil keseluruhan berat struktur ditemukan 16.771,43 Ton/M. Dengan demikian, dari analisis beban gaya lateral ekuivalen (Fi 77,71) didapatkan bahwa, Kontruksi struktur gedung tahan terhadap gempa.
\end{abstract}

Kata Kunci : Gedung, Pondasi, Mayerhoff, Bore Pile. 


\section{PENDAHULUAN}

Peraturan Daerah Kota Kediri Nomor 6 Tahun 2011 tentang pembangunan suatu gedung di Kota Kediri menyebutkan bahwa bangunan gedung adalah salah satu wujud fisik pemanfaatan pada tata ruang. Pembangunan gedung ini tetap mengacu pada pengaturan ruang dengan tetap memperhatikan peraturan perundang-undangan yang berlaku. [1][2] Kegagalan fungsi pondasi pada proses pembangunan sebuah gedung perlu diminimalisir atau perlu adanya upaya untuk menghilangkan risiko [3] dengan meletakkan pondasi bangunan lapisan tanah yang keras/padat (kuat), sehingga dapat mendukung beban bangunan tanpa timbul penurunan yang berlebihan, dan untuk mengetahui letak/kedalaman lapisan tanah padat dengan daya dukung yang cukup besar. [4] Akan tetapi, ada beberapa jenis pondasi yang dibangun tergantung pada kebutuhan yaitu berdasarkan besar beban yang akan diterima dan jenis lapisan tanah yang digunakan sebagai tempat perletakan pada pondasi. [5][6] Pada penggunaan tiang pondasi dalam sebagai bangunan, semua tergantung tanah yang berada dibawah dasar suatu bangunan. Hal yang perlu untuk dicermati adalah jangan sampai pondasi tidak mempunyai daya dukung (bearing capacity) yang amat cukup untuk memikul suatu berat bangunan dan beban yang bekerja[7][8].

Pondasi merupakan bagian terpenting dalam bangunan [9][10][11] sehingga dalam perancangan dan kontruksi pondasi harus dilakukan, diperiksa, dan dipelajari dengan baik.[12] Agar kegagalan pondasi dapat dapat dihindari, maka pondasi bangunan harus diletakan pada lapisan tanah yang cukup keras, padat dan kuat[13][14][15]. Bila beban yang bekerja lebih besar dari gaya dukung tanah maka akan terjadi penurunan (settlement) [16][17] yang diakibatkan oleh runtuhnya bidang tergelincir dan mengakibatkan keruntuhan atau kerusakan bangunan.

Tujuan penelitian ini adalah untuk menghitung daya dukung pondasi tiang yang diterima pada proyek pembangunan Gedung Guest House di Kota Kediri. Tujuan kedua adalah menghitung dimensi dan penulangan pada pondasi tiang. Tujuan ketiga adalah menghitung beban gempa statik terhadap pondasi tiang.

\section{METODE PENELITIAN}

Dalam melakukan penelitian ini, penulis menggumpulkan beberapa bahan untuk menganalisis daya dukung pondasi dengan menggunakan data pondasi tiang. Dalam proses penyusunan penelitian ini, penulis memerlukan data sebagai berikut :
A. Data untuk analisis (sistem pondasi, Pemodelan pondasi, data teknis gedung).
B. Daya dukung standar pondasi bore pile.
C. Sistem struktur atas dan Beban (Material). 
Langkah-langkah yang akan dilakukan pada penelitian berikut ini adalah sebagai berikut :

A. Survey Lokasi, Untuk mengetahui lokasi yang digunakan dalam perencanaan gedung.

B. Menghitung pembebanan yang di terima terutama beban gempa disetiap pondasi dengan mengkalikan dengan volume bangunan beserta berat jenis.

C. Menentukan klarifikasi tanah melalu data SPT yang digunakan pada perencanaan gedung.

D. Menentukan posisi joint pada pondasi bore pile yang akan di gunakan, serta menentukan daya dukung standar pada pondasi bore pile kemudian menghitung penulangan dan dimensi pada pondasi tiang bor.

\section{HASIL DAN PEMBAHASAN}

\subsection{Struktur Atas.}

Seluruh struktur atas menggunakan perhitungan Software Structural Analysis Program (SAP). Sebagian besar di dunia kerja sekarang telah banyak yang memakai software SAP2000 ini, karena lebih praktis, mudah, dan cepat dalam menganalisis struktur bangunan. [18]

Tabel 1. Hasil Perhitungan Berat Tiap Lantai dan Kolom Dengan SAP2000.

\begin{tabular}{|c|c|c|}
\hline \multirow{2}{*}{ Group Name } & Self Mass & Self Weight \\
& Ton $-\mathrm{s}^{2} / \mathrm{m}$ & $1.357,28$ \\
\hline ALL & 135,73 & 288,83 \\
\hline LANTAI 2 & 28,88 & 283,29 \\
\hline LANTAI 3 & 28,33 & 210,52 \\
\hline LANTAI 4 & 21,05 & 213,42 \\
\hline LANTAI 5 & 21,34 & 210,52 \\
\hline LANTAI 6 & 21,05 & 114,43 \\
\hline ROOF TOP & 11,44 & Ton \\
\hline
\end{tabular}

Sumber : Software Structural Analysis Program (SAP2000).

\subsection{Konsistensi Tanah.}

Tanah adalah bahan organik dan endapan-endapan yang relatif lepas (loose) yang terletak diatas batuan dasar (bedrock). [19] Ikatan antara butiran yang relatif lemah dapat disebebkan oleh karbonat, zat organik, atau oksida-oksida yang mengendap diantara partikel- 
partikel. [20] Sedangkan tanah terangkut terbentuk dari pelapukan pada suatu lokasi yang telah terangkut oleh air, angin, es ataupun gaya. [21] Tanah yang mempunyai daya dukung yang amat cukup memikul berat bangunan dan seluruh yang bekerja berada pada lapisan yang sangat amat dalam dari permukaan tanah dengan kedalaman $>8 \mathrm{~m}$. [22] dan untuk menghitung kekuatan tanah maka dignakan rumus Daya dukung tiang berdasarkan N SPT : [23]

$$
P a=\frac{q c \times A p}{F k 1}+\frac{E^{\prime} 1 f i \times A s t}{F K 2}
$$

Tabel 2. Hubungan Antara N-SPT Dengan Tingkat Kepadatan.

\begin{tabular}{|c|c|c|c|c|c|c|c|c|}
\hline \multirow{2}{*}{ No } & \multicolumn{4}{|c|}{ Tanah Berbutir Kasar } & \multicolumn{3}{c|}{ Tanah Butiran Halus } \\
\cline { 2 - 9 } & \multicolumn{3}{|c|}{ N-SPT (Bpf) } & Kepadatan & \multicolumn{2}{c|}{ N-SPT (Bpf) } & Kepadatan \\
\hline 1 & & $<$ & 4 & Amat lepas & & $<$ & 2 & Amat lepas \\
\hline 2 & 4 & - & 10 & Lepas & 2 & - & 4 & Lepas \\
\hline 3 & 10 & - & 30 & Agak padat & 4 & - & 8 & Agak padat \\
\hline 4 & 30 & - & 50 & Padat & 8 & - & 15 & Padat \\
\hline 5 & & $>$ & 50 & Amat Padat & 15 & - & 30 & Amat Padat \\
\hline 6 & & - & & - & & $>$ & 30 & Keras \\
\hline
\end{tabular}

Sumber : Analisa N-SPT Dengan Kepadatan.

\subsection{Penentuan Jenis Tanah.}

Apabila untuk setebal maksimum $30 \mathrm{M}$ paling atas dipenuhi syarat-syarat yang tercantum dalam Tabel 3. berikut. [24]

Tabel 3. Penentuan Jenis - Jenis Tanah.

\begin{tabular}{|c|c|c|c|c|}
\hline \multirow{2}{*}{ No } & \multicolumn{2}{|c|}{ Tanah Berbutir Kasar } & \multicolumn{2}{|c|}{ Tanah Butiran Halus } \\
\hline & $\mathrm{N}-\mathrm{SPT}(\mathrm{Bpf})$ & \multirow{2}{*}{$\begin{array}{l}\text { Kepadatan } \\
\text { Amat lepas }\end{array}$} & $\mathrm{N}-\mathrm{SPT}(\mathrm{Bpf})$ & \multirow{2}{*}{$\begin{array}{l}\text { Kepadatan } \\
\text { Amat lepas }\end{array}$} \\
\hline 1 & & & 2 & \\
\hline 2 & 4 & Lepas & 4 & Lepas \\
\hline 3 & 10 & Agak padat & 8 & Agak padat \\
\hline 4 & 30 & Padat & 15 & Padat \\
\hline 5 & & Amat Padat & 30 & Amat Padat \\
\hline 6 & & - & 30 & Keras \\
\hline
\end{tabular}

Sumber : Analisa Penentuan Jenis Tanah. 


\subsection{Daya Dukung Tiang Tunggal.}

Daya dukung ijin tiang tekan menurut dengan metode meyerhoff [25] adalah sebagai berikut :

$$
P a=\frac{q c \times A p}{F K 1}+\frac{T f \times A s t}{F k 2}
$$

\begin{tabular}{|c|c|c|}
\hline Dimana & $\mathrm{P}_{\mathrm{a}}$ & $=$ Daya dukung ijin tekan tiang. \\
\hline & $\mathrm{Q}_{\mathrm{c}}$ & $=20 \mathrm{~N}$ untuk Silt/Clay $40 \mathrm{~N}$ untuk Sand. \\
\hline & $\mathrm{N}$ & $=$ Nilai N SPT. \\
\hline & Ap & $=$ Lias penampang tiang. \\
\hline & Ast & $=$ Keliling penampang tiang. \\
\hline & Ii & $=$ Panjang segmen tiang yang tertinjau. \\
\hline & fi & $=$ Gaya geser pada selimut sigma tiang. \\
\hline & & $=\mathrm{N}$ maksimum $12 \mathrm{Ton} / \mathrm{M}^{2}$, untuk Silt $/$ Clay. \\
\hline & & $=\mathrm{N} / 5$ maksimum 10 Ton $/ \mathrm{M}^{2}$, untuk Sand. \\
\hline & FK1, FK2 & $=$ Faktor keamanan 3 dan 5. \\
\hline
\end{tabular}

Perhitungan pada kedalaman $26 \mathrm{M}$.

$\begin{array}{ll}\text { Diameter } & =1 . \\ \text { Ap } & =\pi \mathrm{r}^{2} . \\ & =3,14 \quad \mathrm{x} \quad 0,5^{2} . \\ & =0,785 \mathrm{M}^{2} . \\ & =\pi \mathrm{d} . \\ & =3.14 \quad \mathrm{x} \quad 1 . \\ & =3,14 \quad \mathrm{M} . \\ \mathrm{N} & =26 . \\ \text { Qc } & =20 \quad \mathrm{x} \quad \mathrm{N} \mathrm{SPT} . \\ & =20 \quad \mathrm{x} \quad 26 . \\ \text { Li } & =520 \quad \text { Ton/M } . \\ \text { fi } & =3 \mathrm{M} . \\ \text { lifi } & =26 \text { Ton } / \mathrm{M}^{2} . \\ & =3 \quad \mathrm{x} \quad 26 . \\ \text { flifi } & =38 . \\ & =388,2 \text { Ton. } \\ \text { Pal } & =\frac{q c x A p}{F k 1}+\frac{E^{\prime} 1 f i x A s t}{F K 2} .\end{array}$




$$
\begin{aligned}
\mathrm{Pal} & =\frac{500 \times 0,785}{3}+\frac{388,2 \times 3,14}{5} . \\
\mathrm{Pal} & =374,6229 \mathrm{Ton} .
\end{aligned}
$$

\subsection{Perhitungan Dimensi Dan Penulangan Tiang Bor 1 Pile.}

Pada suatu komponen struktur non - prategang dan tulangan sengkang pengikat, kuat tekan aksial terfaktor $\Phi$ Pn tidak boleh diambil lebih dari : [24]

$$
\Phi(P n 9 \max )=0,80 . \Phi .\left\{0,85 . f c^{\prime}(A g-A s t)+\text { Ast. } f y\right\}
$$

Diketahui :

P Kolom $=18,52$ Ton
A. Taksir berat sendiri pile cap :
B. Akibat P :

$$
\begin{aligned}
& =5 \% \quad \mathrm{x} \quad \mathrm{P} \text { kolom. } \\
& =5 \% \quad \mathrm{x} \quad 18,52 . \\
& =0,93 \text { ton. }
\end{aligned}
$$

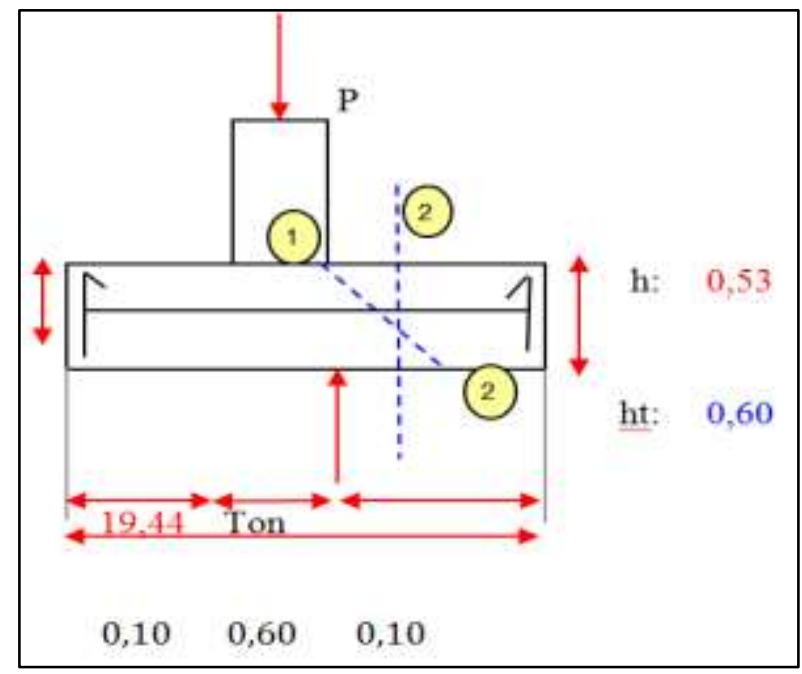

$=18,52+0,93 / 1$

$=19,44 / 1$

$=19,44$ ton

1. Check Geser Potongan $2-2$.

$$
\begin{aligned}
\mathrm{D} 2-2= & 19,44+((2,4 \times(0,80) \times \\
& 0,60 \times(0,10-0,5 \times 0,53)) . \\
\mathrm{D} 2-2= & 19,44+(-0,19) . \\
= & 19,25 \mathrm{Ton} . \\
\mathrm{Tbu}= & 1,05 \times 19,44 \times 1000: 0,9 \\
& :(0,80 \times 100):(0,53 \times 100) \\
\mathrm{T} \text { bu }= & 5,35 \mathrm{~kg} / \mathrm{cm}^{2}<11,00 \mathrm{~kg} / \mathrm{cm}^{2} \\
= & \text { Tebal OKE.. } ! !
\end{aligned}
$$

2. Penulangan Pile Cap.

$$
\begin{aligned}
\mathrm{q} & =\text { berat sendiri pile cap. } \\
& =0,60 \times 0,80 \times 2,40 . \\
& =1,152 \mathrm{Ton} / \mathrm{M} . \\
\mathrm{M} 1-1 & =0,5 \times 1,152 \times 0,01 \\
& =0,576 \times 0,01 \\
& =0,57 \text { ton } / \mathrm{m} \\
\mathrm{Cu} & =24,17 \text { (dari tabel wiratma) } \\
\mathrm{d} & =0,20 \text { ( Pada prakteknya, tul.tekan diambil } 0,2 \text { tulangan tarik) }
\end{aligned}
$$

Apabila tebal tidak ada maka diambil 1 minimum

q. $\mathrm{mm}=0,0025(\mathrm{cu}>5.51)$ 


\section{- Catatan:}

○ Untuk beban gempa ( $\mathrm{k}=0,6 ; \mathrm{Mu}=1,05 \mathrm{M} ; \mathrm{Du}=0,50 \mathrm{D})$

○ Untuk beban umum $(\mathrm{k}=0,5 ; \mathrm{Mu}=1,50 \mathrm{M} ; \mathrm{Du}=1,50 \mathrm{D})$

\subsection{Respon Spectrum Pada Gempa.}

Untuk menemukan rencana pengaruh struk gedung yaitu berupa beban geser dasar nominal statik ekuivalen pada struktur beraturan, gaya geser nominal sebagai respon dinamik ragam pertama pada struktur gedung tidak beraturan dan gaya geser dasar gedung nominal sebagai respon dinamik seluruh ragam yang berpartisipasi pada struktur gedung . masingmasing memiliki wilayah gempa gempa di tetapkan pada respon spectrum gempa . berikut adalah spectrum wilayah gempa di Indonesia, [26].

Tabel 4. Berat Struktur Per - Lantai.

\begin{tabular}{|c|c|c|c|c|}
\hline No & Lantai (i) & Tinggi zi (m) & Berat Wi (ton) & Wi . Zi (ton.m) \\
\hline 1 & Roof Top & 22,95 & 114,43 & $2.626,24$ \\
\hline 2 & Lantai 6 & 19,50 & 210,52 & $4.105,18$ \\
\hline 3 & Lantai 5 & 16,00 & 213,42 & $3.414,72$ \\
\hline 4 & Lantai 4 & 12,50 & 210,52 & $2.631,53$ \\
\hline 5 & Lantai 3 & 9,00 & 283,29 & $2.549,63$ \\
\hline 6 & Lantai 2 & 5,00 & 288,83 & $1.444,13$ \\
\hline & Total & & $\mathbf{1 . 3 2 1 , 0 1}$ & $\mathbf{1 6 . 7 7 1 , 4 3}$ \\
\hline
\end{tabular}

Sumber : Analisa Penentuan Berat Struktur Lantai.

A. Sistem Struktur arah Sumbu Y $=$ Arah sumbu X.

B. SRPM beton bertulang $\mathrm{T}=0.0731 \times(\mathrm{hn})^{(3 / 4)}=0,77$ detik.

$\mathrm{Tc}=$ WG-2, $\quad$ tanah lunak $=1,00$ detik.

Sehingga :

$$
\mathrm{C}=\mathrm{A} \_\mathrm{m}=2.5 \times \mathrm{A} \_0 \quad=0,50 \mathrm{~g} \text {. }
$$


Tabel 5. Spektrum Respon Gempa Rencana.

\begin{tabular}{|c|c|c|c|c|c|c|}
\hline Wilayah & T.Keras & $\mathrm{Tc}=0,5 \mathrm{det}$ & T.Sedang & $\mathrm{Tc}=0,6 \mathrm{det}$ & T.Lunak & $\mathrm{Tc}=1,0 \mathrm{det}$ \\
\hline Gempa & $A_{m}$ & $A_{r}$ & $A_{m}$ & $A_{r}$ & $A_{m}$ & $A_{r}$ \\
\hline 1 & 0,10 & 0,05 & 0,13 & 0,08 & 0,20 & 0,20 \\
\hline 2 & 0,30 & 0,15 & 0,38 & 0,23 & 0,50 & 0.50 \\
\hline 3 & 0,45 & 0,23 & 0,55 & 0,33 & 0,75 & 0,75 \\
\hline 4 & 0,60 & 0,30 & 0,70 & 0,42 & 0,85 & 0,85 \\
\hline 5 & 0,70 & 0,35 & 0,83 & 0,50 & 0,90 & 0,90 \\
\hline 6 & 0,83 & 0,42 & 0,90 & 0,54 & 0,95 & 0,95 \\
\hline
\end{tabular}

Sumber : Analisa Spektrum Respon Gempa Rencana.

Gaya Lateral Ekivalen, $(f i)$

$$
F_{i}=\left(\frac{W_{i} \cdot z_{i}}{\sum W_{i} \cdot z_{i}}\right) V_{b}
$$

Tabel 7. Gaya Lateral Ekivalen Yang Dikenakan Pada Struktur.

\begin{tabular}{|c|c|c|c|c|c|c|}
\hline No & Lantai (i) & Tinggi zi (m) & Berat Wi (ton) & $W i . Z i$ (ton.m) & $F i$ (ton) & $V i$ (ton) \\
\hline 1 & Roof Top & 22,95 & 114,43 & $2.626,24$ & 12,17 & 12,17 \\
\hline 2 & Lantai 6 & 19,50 & 210,52 & $4.105,18$ & 19,02 & 19,02 \\
\hline 3 & Lantai 5 & 16,00 & 213,42 & $3.414,72$ & 15,82 & 15,82 \\
\hline 4 & Lantai 4 & 12,50 & 210,52 & $2.631,53$ & 12,19 & 12,19 \\
\hline 5 & Lantai 3 & 9,00 & 283,29 & $2.549,63$ & 11,81 & 11,81 \\
\hline 6 & Lantai 2 & 5,00 & 288,83 & $1.444,13$ & 6,69 & 6,69 \\
\hline \multicolumn{3}{|c|}{ Total } & 1.321,01 & $16.771,43$ & 77,71 & \\
\hline
\end{tabular}

Sumber : Analisa Gaya Lateral Ekivalen. 


\section{KESIMPULAN}

Dari hasil perencanaan gedung guest house di kota Kediri maka dapat di simpulkan sebagai berikut ;

1. Kemampuan daya dukung pondasi bored pile terhadap kekuatan tanah adalah sebesar 81,00 Ton, dengan kedalaman $26 \mathrm{M}$, dari permukaan tanah.

2. Berdasarkan hasil perhitungan dimensi dan penulangan tiang Bore Pile maka di dapatkan hasil P 19,44 Ton untuk satu tiang dengan kedalaman 26 M. Sedangkan pada penulangan Pile Cap ditemukan q 1,152 Ton/M (berat sendiri). Pada Bore Pile dengan tulangan spiral di temukan hasil data analisis ((D. Beton $600 \mathrm{~mm}$, Selimut $40 \mathrm{~mm}$ ), (D. Tulangan $16 \mathrm{~mm}$, jumlah Tulangan 10), (D. sengkang $10 \mathrm{~mm}$, Spasi $60 \mathrm{~mm}$ )).

3. Berdasarkan hasil keseluruhan berat struktur ditemukan $16.771,43$ Ton/M maka dari analisis dengan beban gaya lateral ekuivalen Fi 77,71 Ton didapatkan bahwa, Kontruksi struktur gedung tahan terhadap gempa.

\section{SARAN}

Berdasarkan analisis perhitungan dan kesimpulan yang ada, maka saran yang dapat disampaikan penulis adalah pada keterkaitan informasi dalam pemilihan karakteristik yang akurat pada tanah sangatlah penting karena menunjang ketelitian analisa, baik data maupun hasil penyelidikan pada tanah dilapangan maupun di laboratorium. Perlu di perhatikan juga besaran pada penurunan tanah yang akan terjadi akibat berat pada struktur yang membebani atau struktur diatasnya perlu diperhitungkan besar penurunan pada tanah yang mungin akan terjadi.

\section{UCAPAN TERIMAKASIH}

Penulis mengucapkan terimakasih kepada kampus Universitas Kadiri (UNIK) yang telah memberikan bimbingan dan pengetahuan untuk menyelesaikan artikel ilmiah ini. 


\section{DAFTAR PUSTAKA}

[1] Y. Rosdiana, “ANALISIS YURIDIS PENYELENGGARAAN IZIN PEMANFAATAN RUANG (Studi Pada Penyusunan Peraturan Daerah Tentang Izin Pemanfaatan Ruang Kabupaten Labuhanbatu)," LEGA LATA, vol. 3, no. 1, pp. 68-80, 2018.

[2] P. Nugroho and A. Sugiri, "Studi Kebijakan Pembangunan terhadap Perubahan Tata Ruang di Kota Semarang,” Ristek, vol. 3, no. 2, pp. 41-51, 2010.

[3] S. Susanto, "PERBANDINGAN FUNGSI KEANGGOTAAN TIPE SEGITIGA DAN TIPE G-BELL TERHADAP ANALISIS RISIKO,” Ukarst, vol. 3, no. 2, pp. 57-67, 2019.

[4] I. R. Gunawan, Pengantar Teknik Fondasi. Yogyakarta: KANISIUS, 1991.

[5] B. Surendro, Rekayasa Fondasi. Yogyakarta: GRAHA ILMU, 2015.

[6] D. Hartanto, Y. Cahyo, S. Winarto, and A. I. Candra, "PERENCANAAN PONDASI TIANG PANCANG PADA GEDUNG SEKRETARIAT DEWAN DPRD KABUPATEN KEDIRI,” Jurmateks, vol. 1, no. 2, pp. 303-312, 2018.

[7] Sardjono, Pondasi Tiang Pancang 1. Surabaya: Sinar Wijaya, 1988.

[8] A. I. Candra, "Analisis Daya Dukung Pondasi Strauss Pile pada Pembangunan Gedung Mini Hospital Universitas Kadiri," Ukarst, vol. 1, no. 1, pp. 63-70, 2017.

[9] W. Jawat, "Metode Pelaksanaan Pekerjaan Pondasi (Studi: Proyek Fave Hotel Kartika Plaza)," Padur. J. Tek. Sipil Univ. Warmadewa, vol. 4, no. 2, pp. 22-34, 2017.

[10] J. Onding, L. S. Balamba, O. B. A. Sompie, and A. N. Sarajar, "Analisis Kestabilan Pondasi Jembatan Studi Kasus : Jembatan Essang-Lalue,” J. Sipil Statik, vol. 1, no. 11, pp. 730-744, 2013.

[11] B. A. Wiratmoko, S. Winarto, and Y. C. SP, "PERENCANAAN PONDASI TIANG PANCANG GEDUNG KETAHANAN PANGAN NGANJUK,” Jurmateks, vol. 2, no. 1, pp. 106-120, 2019.

[12] A. I. Candra, A. Yusuf, and A. R. F, "Studi Analisis Daya Dukung Pondasi Tiang Pada Pembangunan Gedung Lp3m Universitas Kadiri,” CIVILLa, vol. 3, no. 2, pp. 166-171, 2018.

[13] N. Nuryanto and S. Wulandari, "Perencanaan Pondasi Tiang Pada Tanah Lempung," Pros. PESAT, vol. 5, no. 0, pp. 8-9, 2013. 
[14] F. Fahriani and Y. Apriyanti, "ANALISIS DAYA DUKUNG TANAH DAN PENURUNAN PONDASI," Fropil, vol. 3, no. 2, pp. 89-96, 2015.

[15] I. Mustofa, S. Winarto, and A. Ridwan, "PERENCANAAN PONDASI TIANG PANCANG PADA GEDUNG UNIVERSITAS TULUNGAGUNG," Jurmateks, vol. 1, no. 2, pp. 216-226, 2018.

[16] R. I. Sophian, "Penurunan Muka Tanah di Kota-Kota Besar Pesisir Pantai Utara Jawa (Studi Kasus: Kota Semarang),” Bull. Sci. Contrib., vol. 8, no. 1, pp. 41-60, 2010, doi: 10.1245/s10434-015-4372-z.

[17] B. A. K. Yulvi Zaika, "Penggunaan geotextil sebagai alternatif perbaikan tanah terhadap penurunan pondasi dangkal," Rekayasa Sipil, vol. 4, no. 2, pp. 91-98, 2010.

[18] W. Dewobroto, "Pemanfaatan software Structural Analysis Program ( SAP ) sebagai media pembelajaran dalam mata kuliah Analisis Struktur Pemanfaatan software Structural Analysis Program ( SAP ) sebagai media pembelajaran dalam mata kuliah Analisis Struktur 1.”2015, doi: 10.13140/RG.2.1.5107.5289.

[19] A. I. Candra, S. Anam, Z. B. Mahardana, and A. D. Cahyono, "Studi Kasus Stabilitas Struktur Tanah Lempung Pada Jalan Totok Kerot Kediri Menggunakan Limbah Kertas,” UKaRsT, vol. 2, no. 2, pp. 88-97, 2018.

[20] H. C. Hardiyatmo, Mekanika Tanah 2 Edisi Kelima. y: Gadjah Mada University Press, 2010.

[21] Joseph E. Bowles, “Analisa dan Desain Pondasi Jilid 1,” Erlangga, Jakarta, no. 9, pp. 1689-1699, 2013.

[22] Joseph E. Bowles, “Analisis dan Desain Pondasi Jilid 2,” 1986.

[23] A. Pamungkas and E. Harianti, Desain Pondasi Tahan Gempa. Yogyakarta: C.V ANDI OFFSET, 2013.

[24] J. H. Schmertmann, "Statics of SPT.," Journal Geotechnical Engineering Division ASCE, vol. 105, no. GT6, Proc Paper 14573. pp. 655-670, 1979, doi: 10.1016/01489062(79)90039-1.

[25] Mayerhoff, "Bearing capacity and sattlement of pile foundations," J. Geotech. Eng. Div., vol. 102, pp. 197-228, 1976.

[26] "STANDART PERENCANAAN KETAHANAN GEMPA UNTUK STRUKTUR BANGUNAN GEDUNG SNI-03-1726-2002.” 2002. 